\title{
Prostate Cancer in the Elderly Patient: Who Qualifies for Treatment?
}

\author{
Martin H Umbehr* and Michael Muntener \\ Department of Urology, City Hospital of Triemli Zurich, Switzerland
}

Submission: February 10, 2017; Published: March 06, 2017

*Corresponding author: Martin H Umbehr, Department of Urology, City Hospital of Triemli Zurich, Switzerland, Tel: +41 4441648 68; Fax: +41 44 41648 61; Email: martin.umbehr@triemli.zuerich.ch /mumbehr@hotmail.com

\section{Introduction}

Prostate cancer (PCa) is the most common cancer in men and the second most common cause of cancer death with increasing incidence and prevalence during aging [1]. Due to demographic changes and increasing longevity, more and more men are confronted with this disease and its consequences. It is very important to understand, that prostate cancer morbidity is a much more relevant problem than it is actual mortality. Many more men suffer from complications of the disease (i.e. outflow obstruction of the upper and lower urinary tract, hematuria, bone metastases with pain, pathological fractures and spinal cord infiltration) or the adverse effects of treatments than men who ultimately die from it [2]. Hence, with higher age, the loss of quality of life is increasingly more important than the loss of quantity of life. Overall, it is a growing medical and socioeconomical problem. Specific treatment algorithms for elderly men with PCa must be established. Even some elderly patients may benefit from active treatment, however, a very careful patient selection must be performed in this subpopulation to avoid over- as well as under treatment [3]. Patient characteristics as well as tumor biology must be taken into account in order to tailor the treatment.

\section{Assessment of the Elderly Patients Risk Profile}

In clinical practice, there remain the difficult question: which patient can profit from active treatment, respectively and at least as important, which patient will see more harm than benefit from treatment? Whereas it is relatively easy to assess and categorize the aggressiveness of the cancer [4], it is much more challenging doing the same for the patient. Unfortunately, there exist no easily applicable triage tools for such an assessment and to guide ultimately treatment decisions in these patients. Chronological age alone is often not sufficient and clinical gut feeling concerning the biology of the patient can be very misleading. Nevertheless, in terms of practicability and as a very rough pattern, patient's $\geq 75$ years can be taken as the target population keeping clearly in mind, that this population is much more heterogeneous than younger populations. Hence, whenever treatment comes into discussion in elderly patients an assessment of the patient's biology and life expectancy should be performed.

A multidimensional geriatric assessment including functionality and mobility, psyche and cognition, co-morbidity as well as social and nutritional status is of great help [3]. Today, there exists valuable and valid assessment instruments helping to uncover primarily unrecognized deficiencies [5,6] and to graduate elderly patients into risk-groups (fit; limited; frail) [3]. Of course, the assessment is a time consuming process and exceeds the resources in the daily practice. Further and mainly, the interpretation of findings in the clinical context should been left in the hands of the corresponding experts, the geriatric colleagues. Whereas fit patients with a life expectancy of over 10 years can benefit for treatments comparable to younger patients, frail patients with very limited life expectancy will hardly benefit of aggressive treatment since adverse events surpasses in most cases the potential benefits. The Society of Geriatric Oncology Prostate Cancer Working Group published recently their corresponding recommendations [7].

\section{How to Proceed in Clinical Practice?}

Elderly, asymptomatic patients without the diagnosis of prostate cancer should not been screened for the disease, since the probability detecting insignificant PCa is very high. However, if patients suffer from symptoms like urinary outflow retention, hematuria, skeletal pain or unclear reduction of the general state of health, the potential presence of PCa is underlying cause for the bother should been considered. According to an autopsy study in the US, the occult prevalence of prostate cancer in the age of 71-80 years reaches $83 \%$ [8], hence, diagnosis should be confirmed or ruled out beginning with PSA test, DRE and in case of increased suspicion, prostate biopsy and imaging, respectively.

In case of localized PCa the indication for a local treatment in curative intent must be placed with special reservation. If at all, only fit patients with a life expectancy of over 10 years and 
aggressive PCa do qualify. In all other cases, treatment intention should be symptom oriented; PSA monitoring in intermediate to high risk PCa however is indicated so to not miss progression into metastasized stage.

In case of metastasized PCa, actually all patients from fit to frail can benefit from palliative treatment. Importantly, pure PSA manipulation should be avoided and indication for the initiation of a treatment would be proven osseous metastases or symptomatic progression. However, also in here, the aggressiveness must been tailored to the individual patient. First line treatment would be, like in younger patients, androgen deprivation therapy (ADT) [7]. It should been considered that this treatment is associated with higher risk of osteoporosis, metabolic syndrome and cardiovascular events especially in elderly patients [9], hence, an anti-reabsorbing therapy with Denosumab as well as supplementation of calcium and vitamin D3 should be established. Recently, it could have been shown in a phase III trial, that an early systemic therapy during the hormone sensitive phase of PCa with docetaxel in combination with ADT can improve survival substantially and that elderly men with good performance status can benefit as much as younger men [10], especially in case of high tumor burden. On the other side, frail patient will not benefit since adverse effect of treatment will outweigh potential benefits. In case of castration-resistant PCa it has been shown that also elderly patients can benefit from advanced systemic therapy (chemotherapy or advanced hormonal manipulation) [11-15], however, the consideration of the overall situation and the risk profile of the patient becomes increasingly important. Additionally, in this situation a discussion of principles, optimally in presence of the patient and his relatives at the latest should been performed to clarify the goals and to give a realistic summary of the possible and clinical meaningful therapy-options in the future. It is on an individual but also socio-economic point of view very important, to remove unrealistic ideas and to organize symptom oriented palliative treatment in and at the right time.

\section{Conclusion}

The prevalence of PCa in elderly men is very high. The appearance of the disease is diverse and reaches from asymptomatic and unrecognized up to aggressive and life threatening. Also elderly man can benefit from treatment, in very selected patients even in case of localized disease, in most patients in case of metastasized disease. However, since the population of elderly men is heterogeneous any attempt of treatment must been considered carefully with the goal to avoid over- but also under-treatment. The very high rate of morbidity of the disease must been kept seriously in mind, since complications of $\mathrm{PCa}$ and its associated loss in quality of life weights for most elderly men more than loss in quantity of life. A geriatric assessment is of great value in almost all cases to tailor treatment aggressiveness in accordance to the patient's individual risk profile. At the latest, in case of castration resistant PCa unrealistic goals of advanced treatment options must been removed and symptom-oriented palliative treatment organized in and at the right time.

\section{References}

1. Siegel R, Naishadham D, Jemal A (2013) Cancer statistics, 2013. CA Cancer J Clin 63(1): 11-30.

2. Popiolek M, Rider JR, Andren O, Andersson SO, Homeberq L, et al. (2013) Natural History of Early, Localized Prostate Cancer: A Final Report from Three Decades of Follow-Up. Eur Urol 63(3): 428-435.

3. Chunkit Fung, William Dale, Supriya Gupta Mohile (2014) Prostate Cancer in the Elderly Patient. J Clin Oncol 32: 2523-2530.

4. D'Amico AV, Moul J, Carroll PR, Sun L, Lubeck D, et al. (2003) CancerSpecific Mortality After Surgery Or Radiation For Patients With Clinically Localized Prostate Cancer Managed During The ProstateSpecific Antigen Era. J Clin Oncol 21(11): 2163-2172.

5. Hurria A, Gupta S, Zauderer M, ZukerMan EL, Cohen HJ, et al. (2005) Developing a Cancer-Specific Geriatric Assessment: A Feasibility Study. Cancer 104: 1998-2005.

6. Mohile S, Dale W, Hurria A (2012) Geriatric Oncology Research to Improve Clinical Care. Nat Rev Clin Oncol 9(10): 571-578.

7. Droz JP, Balducci L, Bolla M, Emberton M, Fitzpatrick JM, et al. (2010) Management of Prostate Cancer in Older Men: Recommendations of a Working Group of the International Society of Geriatric Oncology. BJU Int 106(4): 462-469.

8. Haas GP, Delongchamps N, Brawley OW, Wang CY, de la Roza G (2008) The Worldwide Epidemiology Of Prostate Cancer: Perspectives From Autopsy Studies. Can J Urol 15(1): 3866-3871.

9. Mohile SG, Mustian K, Bylow K, Hall W, Dale W (2009) Management of Complications of Androgen deprivation therapy in the older man. Crit Rev Oncol Hematol 70(3): 235-255.

10. Christoper Sweeney, Yu-Hui Chen, Michael Anthony Carducci, Glenn Liu, Dravid Frasier Jarrarad, et al. (2014) Impact on Overall survival (OS) with chemohormonal therapy versus hormonal therapy for Hormone-Sensitive Newly Metastatic Prostate Cancer (Mprca): An ECOG-Led Phase III Randomized Trial. ASCO Annual Meeting.

11. De Bono JS, Logothetis CJ, Molina A, Fizazi K, North S, et al. (2011) Abiraterone and Increased Survival in Metastatic Prostate Cancer. N Engl J Med 364(21): 1995-2005.

12. De Bono JS, Oudard S, Ozguroglu M, Hansen S, Machiles JP, et al. (2010) Prednisone Plus Cabazitaxel or Mitoxantrone For Metastatic Castration-Resistant Prostate Cancer Progressing After Docetaxel Treatment: A Randomised Open-Label Trial. Lancet 376(9747): 11471154.

13. Ryan CJ, Smith MR, de Bono JS, Molina A, Loqothetics CJ, et al (2013) Abiraterone in Metastatic Prostate Cancer without Previous Chemotherapy. N Engl J Med, 368(2): 138-148.

14. Scher HI, Fizazi K, Saad F, Taplin ME, Sternberq CN, et al. (2012) Increased Survival with Enzalutamide in Prostate Cancer After Chemotherapy. N Engl J Med 367(13): 1187-1197.

15. Tannock IF, de Wit R, Berry WR, Horti J, Pluzanska A, et al. (2004) Docetaxel Plus Prednisone or Mitoxantrone Plus Prednisone for advanced Prostate Cancer. N Engl J Med 351(15): 1502-1512. 
This work is licensed under Creative Commons Attribution 4.0 License DOI: 10.19080/JOJUN.2017.2.555581
Your next submission with Juniper Publishers will reach you the below assets

- Quality Editorial service

- Swift Peer Review

- Reprints availability

- E-prints Service

- Manuscript Podcast for convenient understanding

- Global attainment for your research

- Manuscript accessibility in different formats

( Pdf, E-pub, Full Text, Audio)

- Unceasing customer service

Track the below URL for one-step submission https://juniperpublishers.com/online-submission.php 